\title{
NUGAROS SKAUSMO, KŪNO SVORIO IR LIEMENS RAUMENŲ STATINĖS IŠTVERMĖS SĄSAJOS
}

\author{
Lietuvos kūno kultūros akademija ${ }^{1}$, Kaunas, Šiauliu reabilitacijos centras ${ }^{2}$, Šiauliai, Lietuva
}

\begin{abstract}
Dudonienė Vilma. Biomedicinos mokslų daktarè. Lietuvos kūno kultūros akademijos Taikomosios fiziologijos ir kineziterapijos katedros docentè. Mokslinių tyrimų kryptis — nugaros skausmo gydymas stuburo stabilizavimo pratimais.
\end{abstract}

\section{SANTRAUKA}

Nutukimas ir nugaros skausmas yra šiuolaikinès visuomenès problema. Mokslininkai nesutaria dèl nugaros skausmo ir nutukimo priklausomybès teoriju (Guo et al., 2008).

Tyrimo tikslas — patikrinti, ar tikrai per didelis küno svoris, didele liemens apimtis yra nugaros skausmo atsiradimo priežastis.

Buvo tiriami 86 tiriamieji, suskirstyti $\mathfrak{i}$ dvi grupes pagal nugaros skausmo pasireiškima: kontrolinę grupe (30 tiriamuju, kurie neturejjo jokiu nusiskundimu nugaros skausmu) ir tiriamaja (56 tiriamieji, kenčiantys nugaros skausma). Tyrimas atliktas Śiauliu reabilitacijios centre. Buvo nustatomas tiriamuju kūno masès indeksas, liemens ir klubu apimtis, liemens ir klubu apimties santykis, liemens raumenu statine ištvermé. Tiriamuju nugaros skausmas buvo vertinamas naudojant McGill skausmo klausimyna ir Oswestry negalios indeksq.

Tyrimo rezultatu analizè parodè, kad nutukimas nèra pagrindinè nugaros skausma lemianti priežastis. Tarp kūno masès indekso ir nugaros skausmo reikšmingos priklausomybès nenustatyta. Moteru, besiskundžiančiu nugaros skausmu, liemens apimtis buvo didesnè $(p<0,01)$ nei nesiskundžiančiuju. Kenčiančiu nugaros skausma vyru liemens ir klubu apimties santykis didesnis nei nesiskundžiančiuju $(p<0,05)$. Liemens raumenu statinè ištvermé buvo didesné tu tiriamuju, kurie nesiskunde nugaros skausmu ( $<<0,01)$.

Raktažodžiai: nugaros skausmas, kūno masès indeksas, liemens ir klubu apimties santykis, McGill skausmo klausimynas, Oswestry negalios indeksas.

\section{IVADAS}

A patinès stuburo dalies skausmas ir nutukimas yra svarbios klinikinès, socialinès, ekonominès ir sveikatos apsaugos problemos, kurios gali paveikti visas amžiaus grupes (Leboeuf-Yde et al., 2008). Nutukimo paplitimas per pastaruosius du dešimtmečius išaugo tris kartus (Manchikanti et al., 2001). Tiriamujų, kurie skundžiasi nugaros skausmu, amžius vis jaunèja, ir tai tampa ne tik pagyvenusių, bet ir jaunu žmonių sveikatos problema. Skausmą dažniausiai patiria darbingo amžiaus žmonès (Deyo, Weinstein, 2001). Daug diskutuojama apie nugaros skausmą, jo priežastis ir įvairovę. Žmonių, kurie skundžiasi nugaros skausmu, vis daugèja. Nugaros skausmą per savo gyvenimą patiria apie $80 \%$ moterų ir 70\% vyrų. Sparčiai didejantys skaičiai ir jaunėjantis besiskundžiančiujuc amžius rodo, kad ši problema aktuali (Rubin, 2007). Viena iš 
nugaros skausmo priežasčiu — per didelè kūno masè (Manchikanti et al., 2001). Yra kelios hipotezès, susijusios su nutukimu ir apatinès stuburo dalies skausmo atsiradimu. Padidejusi mechaninè apkrova dèl antsvorio, medžiagu apykaitos sutrikimai - tai veiksniai, galintys lemti nugaros skausmo atsiradimą (Leboeuf-Yde et al., 2008). Dèl padidejusio kūno svorio ir nugaros skausmo pasireiškimo suvaržomas jaunų, darbingo amžiaus žmonių gebejjimas atlikti kasdienę veiklą, galimi didesni ar mažesni sveikatos sutrikimai, dažniau atsiranda nerimas ir depresija, padaugèja finansinių problemų tiek dèl prarasto darbingumo, tiek dèl ligos bei jos komplikaciju gydymo išlaidu.

Tyrimo tikslas - nustatyti nugaros skausmo, nutukimo ir liemens raumenu statinès ištvermès rodiklių sąsajas.

\section{TYRIMO METODIKA}

Tyrimas vyko $2008-2009$ m. Šiauliu reabilitacijos centre. Buvo tiriami 86 asmenys (40 vyru ir 46 moterys). Pagal nugaros skausmo pasireiškimą tiriamieji buvo suskirstyti i dvi grupes: pirmą kontrolinę (30 tiriamujų, kurie nesiskunde nugaros skausmu) ir antrą tiriamają (56 tiriamieji, kenčiantys nugaros skausma) (1 pav.). Tiriamuju amžius svyravo nuo 21 iki 67 metu. Tiriamu grupių rodikliai pateikti 1 lentelèje.

Antsvoris ir nutukimas (2 lent.) buvo nustatomas apskaičiuojant kūno masès indeksą $(\mathrm{KMI}=$ svoris $\left.(\mathrm{kg}) / \mathrm{u} g i \mathrm{~s}\left(\mathrm{~m}^{2}\right)\right)$.

Nutukimas taip pat buvo vertinamas pagal liemens apimti, liemens ir klubų apimties santyki. Liemens apimties vertinimo kriterijai yra šie (Shiri et al., 2008): jei vyru liemens apimtis $94-102 \mathrm{~cm}$, vidutiné rizika nugaros skausmui atsirasti, jei
$102 \mathrm{~cm}$ - labai didelè; jei moterų liemens apimtis $80-88 \mathrm{~cm}$, vidutinè rizika nugaros skausmui atsirasti, jei didesnè nei $88 \mathrm{~cm}$ - labai didelè.

Liemens ir klubų apimties santykio vertinimo kriterijai (Shiri et al., 2008 ) tokie: vyru šis santykis laikomas norma $<0,9$, moteru $<0,85$; per didelis santykis, kai šis vyrų rodiklis yra $>0,9$, moteru $>0,85$.

Liemens raumenų statinès ištvermès vertinimas. Tiriamosios ir kontrolinès grupès tiriamuju pilvo, nugaros, šoninių liemens raumenų statinè ištverme buvo îvertinta stuburo stabilumo testais (McGill, 2007). Testų metu laikas registruojamas sekundèmis.

Nugaros skausmas. Tiriamosios grupès tiriamujų nugaros skausmas buvo vertinamas naudojant McGill skausmo klausimyną ir Oswestry negalios indeksa. Oswestry negalios indekso klausimynu (Magee, 2007) buvo vertinama, kaip nugaros skausmas veikia tiriamojo funkcinę būklę. Vertinimo skale yra nuo 0 iki 50. Kuo mažiau balu surenkama, tuo mažesnis juosmens skausmas ir geresnè tiriamojo funkcinè būklè. Skausmo intensyvumas tyrimo momentu buvo vertinamas McGill skausmo klausimynu (Magee, 2007).

Matematinè statistika. Buvo skaičiuojami ir pateikiami tokie statistiniai rodikliai: aritmetinis vidurkis $(\bar{x})$ ir standartinis nuokrypis (SD). Kokybiniu požymiu dažnumas buvo išreiškiamas procentais, jų statistinis ryšys įvertintas $\chi^{2}\left(c h i^{2}\right)$ kriterijumi. Statistine hipotezè apie lyginamuju grupiu vidurkiu lygybę buvo tikrinta pasitelkiant Stjudento t (Student $t$ ) kriterijų, prieš tai palyginus grupių dispersijas pagal Fišerio F (Fisher $F)$ kriterijų. Reikšmingumo lygmuo $\alpha$, tikrinant statistines hipotezes, pasirinktas 0,05. Duomenu skirtumas laikytas statistiškai reikšmingu, kai $\mathrm{p}<0,05$.

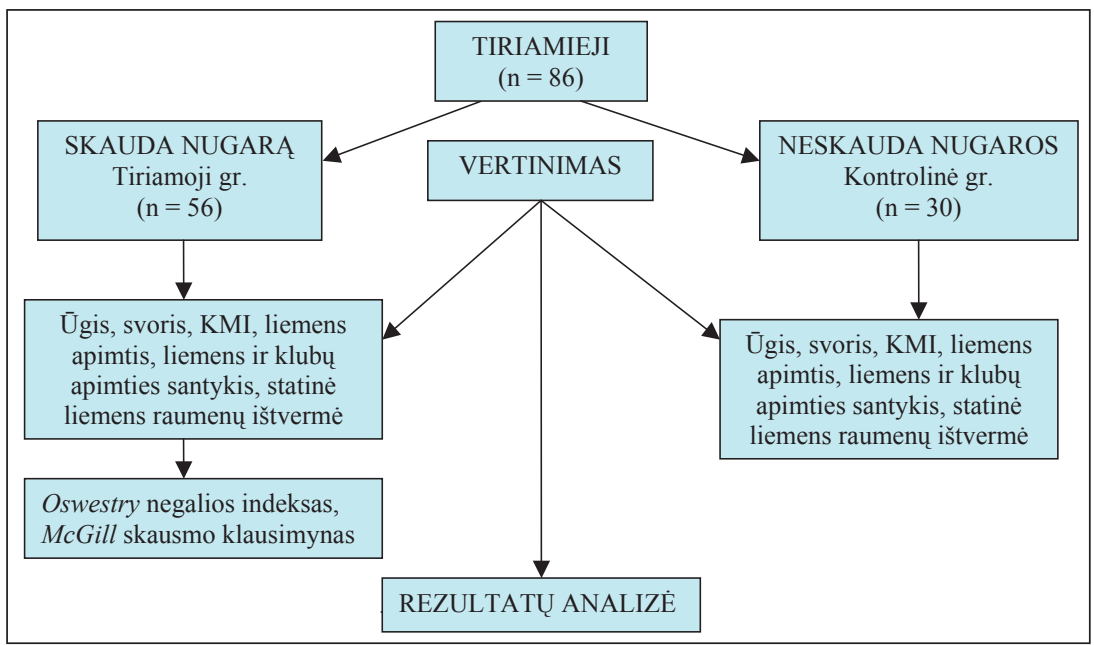




\begin{tabular}{|l|c|c|c|c|}
\hline Grupé & $\begin{array}{c}\text { Amžius, } \\
\mathbf{m .} \pm \text { SD }\end{array}$ & $\begin{array}{c}\text { Ūgis, } \\
\mathbf{c m} \pm \text { SD }\end{array}$ & $\begin{array}{c}\text { Svoris, } \\
\mathbf{k g} \pm \mathbf{S D}\end{array}$ & $\begin{array}{c}\text { KMI, } \\
\mathbf{k g} / \mathbf{m}^{2} \pm \mathbf{S D}\end{array}$ \\
\hline Tiriamoji (n=56;65\%) & $45,3 \pm 2,95$ & $171,8 \pm 1,98$ & $80,0 \pm 3,47$ & $27,1 \pm 0,96$ \\
\hline Kontrolinè (n=30;35\%) & $40,2 \pm 5,16$ & $172,9 \pm 3,12$ & $77,4 \pm 5,53$ & $25,0 \pm 2,18$ \\
\hline Bendrai (n=86; 100\%) & $43,5 \pm 2,67$ & $172,2 \pm 1,69$ & $79,1 \pm 2,98$ & $26,3 \pm 1,0$ \\
\hline
\end{tabular}

\begin{tabular}{|c|c|c|c|c|c|}
\hline \multirow{2}{*}{$\begin{array}{c}\text { KMI, } \\
\mathbf{k g} / \mathbf{m}^{2}\end{array}$} & \multirow{2}{*}{ Vertinimas } & \multicolumn{2}{|c|}{ Tiriamoji grupé } & \multicolumn{2}{|c|}{ Kontrolinè grupé } \\
\cline { 3 - 6 } & Vyrai, \% & Moterys, \% & Vyrai, \% & Moterys, \% \\
\hline$<18,5$ & Mažas svoris & & 3,4 & & \\
\hline $18,5-24,9$ & Normalus & 11,1 & 34,5 & 15,4 & 52,9 \\
\hline $25-29,9$ & Antsvoris & 63,0 & 41,4 & 61,5 & 29,4 \\
\hline $30-34,9$ & I nutukimas & 25,9 & 20,7 & 23,1 & 17,6 \\
\hline
\end{tabular}

\begin{tabular}{|c|c|c|c|c|c|c|}
\hline Liemens & \multicolumn{2}{|c|}{ Norma } & \multicolumn{2}{|c|}{ Antsvoris } & \multicolumn{2}{|c|}{ Nutukimas } \\
\hline Grupè & $\begin{array}{l}\text { Moterys } \\
(\leq 80 \mathrm{~cm})\end{array}$ & $\begin{array}{c}\text { Vyrai } \\
(\leq 93,9 \mathrm{~cm})\end{array}$ & $\begin{array}{c}\text { Moterys } \\
(80-87,9 \mathrm{~cm})\end{array}$ & $\begin{array}{c}\text { Vyrai } \\
(94-101,9 \mathrm{~cm})\end{array}$ & $\begin{array}{l}\text { Moterys } \\
(\geq 88 \mathrm{~cm})\end{array}$ & $\begin{array}{c}\text { Vyrai } \\
(\geq 102 \mathrm{~cm})\end{array}$ \\
\hline Tiriamoji, \% & 6,9 & 37,0 & 48,3 & 33,3 & 44,8 & 29,6 \\
\hline Kontrolinè, \% & 35,3 & 23,1 & 17,6 & 46,2 & 47,1 & 30,8 \\
\hline
\end{tabular}

2 lentelè. Tiriamųjų procentinis skirstinys pagal kūno masès indeksą

\begin{tabular}{|c|c|c|c|c|c|c|}
\hline \multirow{2}{*}{$\begin{array}{r}\text { Liemens ir klubų } \\
\text { apimties } \\
\text { santykis }\end{array}$} & \multicolumn{2}{|c|}{ Norma } & \multicolumn{2}{|c|}{ Antsvoris } & \multicolumn{2}{|c|}{ Nutukimas } \\
\hline & $\begin{array}{r}\text { Moterys } \\
(<\mathbf{0 , 8 0 )}\end{array}$ & $\begin{array}{c}\text { Vyrai } \\
(<0,90)\end{array}$ & $\begin{array}{c}\text { Moterys } \\
(\mathbf{0 , 8 0}-\mathbf{0 , 8 4})\end{array}$ & $\begin{array}{c}\text { Vyrai } \\
(0,90-0,99)\end{array}$ & $\begin{array}{c}\text { Moterys } \\
(\geq \mathbf{0 , 8 5})\end{array}$ & $\begin{array}{c}\text { Vyrai } \\
(\geq 1,00)\end{array}$ \\
\hline Tiriamoji, \% & 20,7 & 18,5 & 20,7 & 66,7 & 58,6 & 14,8 \\
\hline Kontrolinè, $\%$ & 11,8 & 30,8 & 29,4 & 61,5 & 58,8 & 7,7 \\
\hline
\end{tabular}

3 lentelè. Tiriamųjų procentinis skirstinys pagal liemens apimti

\section{REZULTATAI}

Tiriamujų, kurie skundèsi nugaros skausmu, negalia, vertinama Oswestry indeksu, sudarè $27,2 \pm 2,68$ balų. Šios grupès vyrų negalios indeksas $(23,5 \pm 2,86$ balo $)$ buvo reikšmingai $(p<0,05)$ mažesnè nei moteru $(30,6 \pm 4,17$ balo). Daugiau nei puse $(57 \%)$ tiriamosios grupès tiriamuju pagal ši indeksą priskiriami vidutiniam neigalumui, $32 \%$ - minimaliam ir $11 \%$ - sunkiam.

Tiriamosios grupès tiriamujų skausmo intensyvumas, vertintas McGill skausmo klausimynu, siekè $38,2 \pm 2,51$ balo: vyru $-38,0 \pm 3,41$, moteru $-38,3 \pm 3,77$ balo.

Tiriamosios grupès vyrų liemens apimtis buvo $97,3 \pm 3,23 \mathrm{~cm}$, moteru $-88,9 \pm 4,03 \mathrm{~cm}$. Kontrolinès grupès tiriamujų liemens apimties vi- durkis mažai skyrèsi nuo tiriamosios grupès ir buvo: vyru $-98,1 \pm 4,57 \mathrm{~cm}$, moteru $-87,0 \pm$ $4,5 \mathrm{~cm}$. Beveik pusè $(48,3 \%)$ tiriamosios grupès moteru liemens apimtis rode antsvori ir beveik pusei $(47,1 \%)$ kontrolinès grupès vyrų nustatytas nutukimas (3 lent.). Moterų, besiskundžiančių nugaros skausmu, liemens apimtis buvo didesnè $(p<0,001)$ nei nesiskundžiančiujų.

Abiejų grupių tiriamujų liemens ir klubų apimties santykio vidurkis buvo vienodas $-0,9 \pm 0,02$. Didžiausias tiriamuju liemens ir klubų apimties santykis buvo 1,04 , mažiausias - 0,71 .

Liemens ir klubų apimties santykis tarp moterų ir vyru vertinamas skirtingai. Tiriamosios grupès moterų mažiausias šis santykis buvo 0,71 , didžiausias - 0,98. Kontrolinès grupès moteru mažiausias liemens ir klubų apimties santykis buvo 


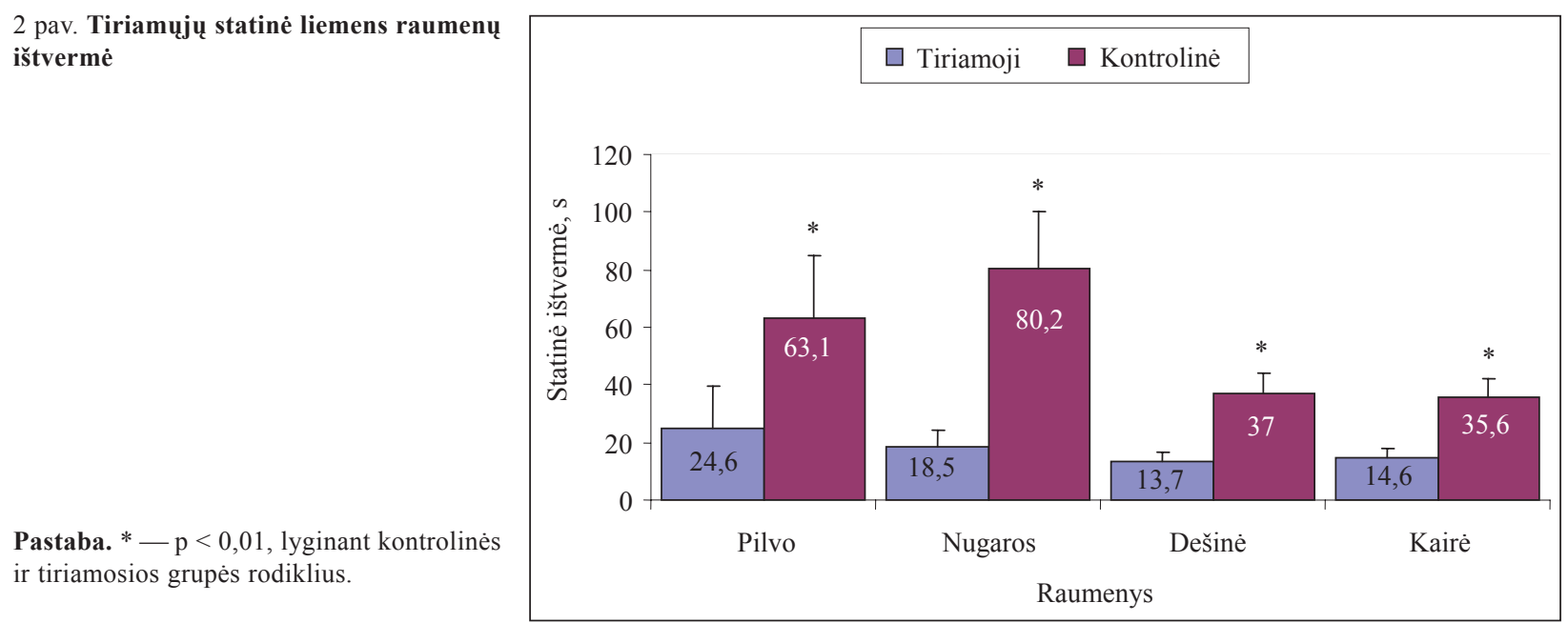

0,76, didžiausias - 0,97. Abiejų grupių tiriamujų procentinis skirstinys pagal liemens ir klubų apimties santyki pateiktas 4 lentelejje. Vyru, kenčiančiu nugaros skausmą, liemens ir klubų apimties santykis buvo didesnis nei nesiskundžiančiuju šiuo skausmu $(\mathrm{p}<0,05)$.

Tiriamosios grupès tiriamujų, besiskundžiančių nugaros skausmu, pilvo, nugaros, liemens dešinès ir kairès pusių statinè ištvermè buvo daug prastesnè nei kontrolinès grupès $(\mathrm{p}<0,01)(2$ pav.).

\section{REZULTATU APTARIMAS}

Nutukimo ir apatinès nugaros dalies skausmo sąsaja jau daugeli metu yra tyrèjų domèjimosi objektas. Didejanti liemens apimtis ir juosmeninè lordozè leidžia tyrèjams daryti išvadą, kad žmonès su antsvoriu yra labiau linkę skųstis nugaros skausmu. Praejusio amžiaus viduryje mokslininkai teigè, kad tarpslankstelinių diskų degeneracijos paplitimas nesusijęs su nutukimu, bet praejus dvidešimčiai metų nuomonè pasikeitè, nes buvo nustatyta, kad 70\% kenčiančių nugaros skausmą klasifikuojami kaip turintys antsvori (Mirtz, Greene, 2005). Intuityviai manoma, kad apatinès nugaros dalies skausmas susijęs su padidejusiu kūno svoriu. Tyrèjai nustato nugaros skausmo ir nutukimo sąsają, tačiau ji nėra reikšminga (Bener et al., 2003; Yamakawa et al., 2004).

Mūsų tiriamujų, kurie skundèsi apatinès stuburo dalies skausmu, amžius buvo 45,3 $\pm 11,26 \mathrm{~m}$. Daugelio tyrèjų nuomone, nugaros skausmo pasireiškimo pikas - 45-tieji gyvenimo metai (Deyo, Weinstein, 2001; Cohen et al., 2001).

Nutukimas nustatomas tada, kai KMI būna didesnis nei $30 \mathrm{~kg} / \mathrm{m}^{2}$, o antsvoris - kai KMI yra tarp 25 ir $30 \mathrm{~kg} / \mathrm{m}^{2}$. Antsvoris būdingesnis vyrams, o nutukimas — moterims. Kai kūno svo- ris padidèja $20 \%$, vyrų mirštamumas išauga $20 \%$, moteru $-10 \%$. Be to, nustatyta, kad vyru, vyresnių nei 40 metu amžiaus, antsvoris, nutukimas ir rūkymo stažas ilgesnis nei 20 metų (surūkant po 20 cigarečiu per dieną) padidina riziką nugaros ligoms pasireikšti (Kostova, Koleva, 2001).

Liemens apimtis ir KMI rodo skirtingus nutukimo požymius. Liemens apimtis rodo tiek visceralini, tiek poodini riebalu kiekį (Jia et al., 2003). KMI nerodo riebalinio audinio pasiskirstymo (Dalton et al., 2003), kai tuo tarpu liemens apimti geriau matuoti vertinant pilvinį nutukimą (Snijder et al., 2006).

Mūsų tyrimo metu tarp skirtingos lyties tiriamujų kūno masės indekso ir nugaros skausmo reikšmingos priklausomybès nebuvo nustatyta. T. A. Mirtz ir L. Greene (2005) teigia, kad nugaros skausmo atsiradimo vidutine rizikos tikimybe gali atsirasti tuomet, kai kūno masès indeksas yra $>30 \mathrm{~kg} / \mathrm{m}^{2}$, o daugiau nei vidutinè - kai $\mathrm{KMI}>40 \mathrm{~kg} / \mathrm{m}^{2}$. Mūsų tirtu žmonių, kenčiančių nugaros skausmą, KMI indeksas buvo 27,1 \pm $0,96 \mathrm{~kg} / \mathrm{m}^{2}$. Tik $15 \%$ tiriamosios grupès tiriamuju KMI svyravo tarp $30-34,9 \mathrm{~kg} / \mathrm{m}^{2}$. Galima daryti prielaida, kad galbūt dèl to nebuvo nustatyta kūno masės indekso ir nugaros skausmo rodiklių sąsajų.

Padidèjusi liemens apimtis gali būti nugaros skausmo atsiradimo priežastimi. Tai patvirtino ir R. Shiri ir bendraautoriu (2008) tyrimas. Mokslininkai teigia, kad pilvinis nutukimas lemia nugaros skausmo atsiradimą, bet tai būdingiau moterims nei vyrams. Moterys, kuriu liemens ir klubu apimties santykis yra didesnis kaip 0,85, patenka į rizikos grupę. Mūsų tyrimu nustatyta, kad normalios liemens apimties buvo tik 6,9\% tirtų moterų, besiskundžiančių nugaros skausmu, ir $35,3 \%$ nesiskundžiančiuju. 
Yra mokslinių tyrimų, kurių rezultatai rodo, kad tarp liemens apimties, liemens ir klubų apimties bei nugaros skausmo priklausomybès nèra (Janke et al., 2007). Mūsų tyrimo atveju, vertinant liemens ir klubu apimties santyki, tarp abiejuc grupių tiriamujų skirtumo nenustatyta. J. Guo ir bendraautoriai (2008) teigia, kad KMI indeksas, didesnis nei $24 \mathrm{~kg} / \mathrm{m}^{2}$, o liemens ir klubų santykis - už 0,85 , rodo centrinį nutukimą ar antsvori, kurie didina juosmeninę lordozę bei kryžkaulio pasvirimo kampa, ir tai gali sukelti nugaros skausmą. M. Liuke ir bendraautoriai (2005) teigia, kad KMI, didesnis nei $25 \mathrm{~kg} / \mathrm{m}^{2}$, padidina juosmeninių diskų degeneracijos riziką, o antsvoris jaunam žmogui yra ypač kenksmingas.

Savo tyrimu dar vertinome statinę liemens raumenų ištvermę ir nustatėme, kad nesiskundžiančių nugaros skausmu tiriamuju ji buvo reikšmingai didesnè nei tuc, kurie kentè nugaros skausmą. Galima daryti prielaida, kad tiriamuju, kenčiančių nugaros skausmą, liemens raumenų ištvermè, buvo mažesnè dèl juntamo skausmo, o gal dèl to, kad silpni liemens raumenys neapsaugojo stuburo struktūru nuo apkrovuc. Be to, nustateme, kad tiriamujuc, kurie skundèsi nugaros skausmu, statinè pilvo raumenu ištvermé buvo didesnè nei nugaros, ir tai gali būti viena iš nugaros skausmo atsiradimo priežasčių. Pusiausvyros nebuvimas tarp pilvo ir nugaros raumenų gali būti stuburo segmentų ne- stabilumo priežastimi - dèl to atsiranda stuburo struktūrų pažeidimo rizika (McGill, 2007).

Apibendrinant galima teigti, kad nutukimas negali būti tiesioginè ir pagrindinè nugaros skausmo atsiradimo priežastis, todèl vertinant juosmeninès stuburo dalies skausmo ir nutukimo santykị reikia atsižvelgti ir í socialinius-ekonominius veiksnius, ir gyvenimo būdą (rūkymą ir fizini aktyvuma), ir i kai kurių autorių ypač akcentuojamą paveldimumo veiksni (Flamme, 2005).

\section{IŠVADOS}

Nugaros skausmo intensyvumas tarp lyčių nesiskyrè, tačiau moterų negalios lygis buvo didesnis nei vyru $(\mathrm{p}<0,01)$.

Tarp skirtingos lyties tiriamujų kūno masès indekso ir nugaros skausmo nèra reikšmingos priklausomybės. Moterų, besiskundžiančių nugaros skausmu, liemens apimtis buvo didesnè $(\mathrm{p}<$ $0,001)$ nei nesiskundžiančiuju. Kenčiančių nugaros skausmą vyrų liemens ir klubų apimties santykis buvo didesnis nei nesiskundžiančiuju $(\mathrm{p}<0,05)$.

Tarp statinès liemens raumenų ištvermès ir kūno masès indekso rodiklių reikšmingos sąsajos nèra.

Tiriamujų, kurie skundèsi nugaros skausmu, statinė liemens raumenu ištvermè buvo reikšmingai mažesnè $(p<0,01)$ nei nesiskundžiančiujų.

\section{LITERATŪRA}

Bener, A., Alwash, R., Gaber, T., Lovasz, G. (2003). Obesity and low back pain. Collegium Antropologicum, 27 (1), 95-104.

Cohen, R., Chopra, P., Upshur, C. (2001). Primary care work-up of acute and chronic symptoms. Geriatrics, 56 (11), 26-27, 30, 33-44.

Dalton, M., Cameron, A. J., Zimmet, P. Z. et al. (2003). Waist circumference, waist-hip ratio and body mass index and their correlation with cardiovascular disease risk factors in Australian adults. Journal of Internal Medicine, 254 (6), 555-563.

Deyo, R. A., Weinstein, J. N. (2001). Low back pain. The New England Journal of Medicine, 5, 363-370.

Flamme, C. H. (2005). Obesity and low back pain-biology, biomechanics and epidemiology. Der Orthopäde, 34 (7), $652-657$.

Guo, J. M., Zhang, G. O., Alimujiang. (2008). Effect of BMI and WHR on lumbar lordosis and sacrum slant angle in middle and elderly women. China Journal of Orthopaedics and Traumatology, 21, 30-31.

Janke, A. E., Collins, A., Kozak, A. T. (2007). Overview of the relationship between pain and obesity: What do we know? Where do we go next? Journal of Rehabilitation Research \& Development, 2, 245-262.
Jia, W. P, Lu, J. X, Xiang, K. S. et al. (2003). Prediction of abdominal visceral obesity from body mass index, waist circumference and waist-hip ratio in Chinese adults: Receiver operating characteristic curves analysis. Biomedical and Environmental Sciences, 16 (3), 206-211.

Kostova, V., Koleva, M. (2001). Back disorders (low back pain, cervicobrachial and lumbosacral radicular syndromes) and some related factors. Journal of the Neurological Sciences, 192, 17-25.

Leboeuf-Yde, C., Kjaer, P., Bendix, T., Manniche, C. (2008). Self-reported hard physical work combined with heavy smoking or overweight may result in so-called Modic changes. BMC Musculoskeletal Disorders, 9, $1-11$.

Liuke, M., Solovieva, S., Lamminen, A. et al. (2005). Disc degeneration of the lumbar spine in relation to overweight. International Journal of Obesity (London), 29 (8), 903-908.

Magee, D. J. (2007). Orthopedic Physical Assessment. St. Louis, Missouri: W. B. Saunders company.

Manchikanti, L., Pampati, V., Singh, V. et al. (2001). Evaluation of role of facet joints in persistent low back pain in obesity: A controlled, prospective, comparative evaluation. Pain Physician, 3, 266-272. 
McGill, S. (2007). Low Back Disorders. Evidence - Based Prevention and Rehabilitation. Human Kinetics.

Mirtz, T. A., Greene, L. (2005). Is obesity a risk factor for low back pain? An example of using the evidence to answer a clinical question. Chiropractic \& Osteopathy, $13,1-6$.

Rubin, D. I. (2007). Epidemiology and risk factors for spine pain. Neurologic Clinics, 25, 353-371.

Shiri, R., Solovieva, S., Husgafvel-Pursiainen, K. et al. (2008). The association between obesity and the prevalence of low back pain in young adults: The cardiovascular risk in young Finns study. American Journal of Epidemiology, 167 (9), 1110-1119.

Snijder, M. B., van Dam, R. M., Visser, M. et al. (2006). What aspects of body fat are particularly hazardous and how do we measure them? International Journal of Epidemiology, 35, 83-92.

Yamakawa, K., Tsai, C. K., Haig, A. J., Miner, J. A., Harris, M. J. (2004). Relationship between ambulation and obesity in older persons with and without low back pain. International Journal of Obesity and Related Metabolic Disorders, 28 (1), 137-143.

\title{
INTERRELATIONSHIP BETWEEN BACK PAIN, BODY WEIGHT AND STATIC ENDURANCE OF TRUNK MUSCLES
}

\author{
Vilma Dudoniené $\dot{1}^{1}$, Donata Spudytè ${ }^{2}$ \\ Lithuanian Academy of Physical Education ${ }^{1}$,Kaunas, \\ Šiauliai Rehabilitation Centre ${ }^{2}$ S Šiauliai, Lithuania
}

\begin{abstract}
Obesity and low back pain are common health problems nowadays. Scientists are discussing the theory of low back pain induced by obesity (Guo et al., 2008).

The aim of the research was to verify whether the overweight and a high waist circumference influenced the manifestation of back pain.

86 subjects participated in the study; they were divided into to groups: control (30 subjects without low back pain), and research (56 subjects with low back pain). The investigation was carried out in Šiauliai Rehabilitation Centre. Body mass index, waist and hip circumferences, waist-hip ratio and isometric endurance of trunk muscles were determined. Low back pain was evaluated according to McGill pain questionnaire, and Oswestry disability index was used.

The analysis of study results indicated that obesity was not the main reason of low back pain. There was no relationship between body mass index and low back pain. There was a higher waist circumference among women with low back pain compared to women without pain $(\mathrm{p}<0.01)$, and men with low back pain had higher waist-hip ratio compared to men without low back pain $(p<0.05)$. The endurance of static trunk muscle was greater in people without low back pain $(\mathrm{p}<0.01)$.
\end{abstract} index.

Keywords: back pain, body mass index, waist-hip ratio, McGill pain questionnaire, Oswestry disability

Vilma Dudonienè

Lietuvos kūno kultūros akademija

(Lithuanian Academy of Physical Education)

Sporto g. 6, LT-44221 Kaunas

Lietuva (Lithuania)

Tel +370 37204338

E-mail v.dudoniene@lkka.lt 